\title{
UNEXPLAINED ELECTROCARDIOGRAMS IN THE AFRICAN
}

\author{
BY \\ S. J. POWELL \\ From the Department of Medicine, University of Natal, Durban, South Africa \\ Received June 28, 1958
}

Brink (1951) first described inversion of the $T$ wave in the præcordial leads in apparently healthy Africans. Littmann (1946) had described similar changes found occasionally in healthy adult American Negroes, in whom Goldman (1953) later described S-T segment elevation in the left præcordial leads. Grusin (1954) showed that many African medical patients with or without heart disease had electrocardiograms that are abnormal by accepted standards and fluctuate spontaneously: they could be arbitrarily classified into three patterns.

The following survey was undertaken to ascertain whether similar changes were found in the Natal African.

\section{MATERIAL AND METHODS}

Three groups were investigated. Group 1 consisted of 109 consecutive African male medical admissions. Nine of these were removed from the series because they had clinical evidence of heart disease.

Group 2 consisted of 100 consecutive African male patients admitted with proven amœbic dysentery, without co-existing disease: those treated with emetine were excluded.

Group 3 consisted of 50 African male nursing staff. They underwent full medical examination and were known to have had an adequate European type of diet for not less than three years.

Electrocardiograms were recorded initially in all cases, and were repeated in all those in Group 2 following treatment, the period in hospital being from 10 to 27 days. Emetine was not used in any of them. In many cases found to have abnormal electrocardiograms the effect of exercise and respiration was determined. In other instances serial records were taken. In many cases the heart was screened, and radiographs taken.

In Group 2 the hæmoglobin, white cell count, erythrocyte sedimentation rate, liver function tests, and serum proteins (by chemical fractionation and paper electrophoresis) were estimated on admission and following treatment. Identical investigations were performed on the subjects of Group 3. In addition the serum electrolytes were estimated on the cases in Group 2 on admission and following treatment. In ten instances liver biopsies were performed.

\section{RESULTS}

Abnormal findings were classified according to Grusin's (1954) criteria, although his Pattern 3, consisting of round or flat $\mathrm{T}$ waves in the præcordial leads was not accepted. Such patterns do occur in a few cases, but the criteria for these $\mathrm{T}$ wave abnormalities are not well defined.

Pattern 1. Inverted T waves in the præcordial leads, these being deeply inverted with the S-T segment bowed upwards, the whole deflection being asymmetrical with a longer distal limb and ending in a rounded hump before settling on the isoelectric line.

Pattern 2. S-T segment elevation and tall T waves in the præcordial leads, these consisting of a slowly rising ascending limb and a sharply falling distal limb ending in a $U$ wave.

Pattern 1 and 2. This is a combination of Pattern 1 and Pattern 2. 


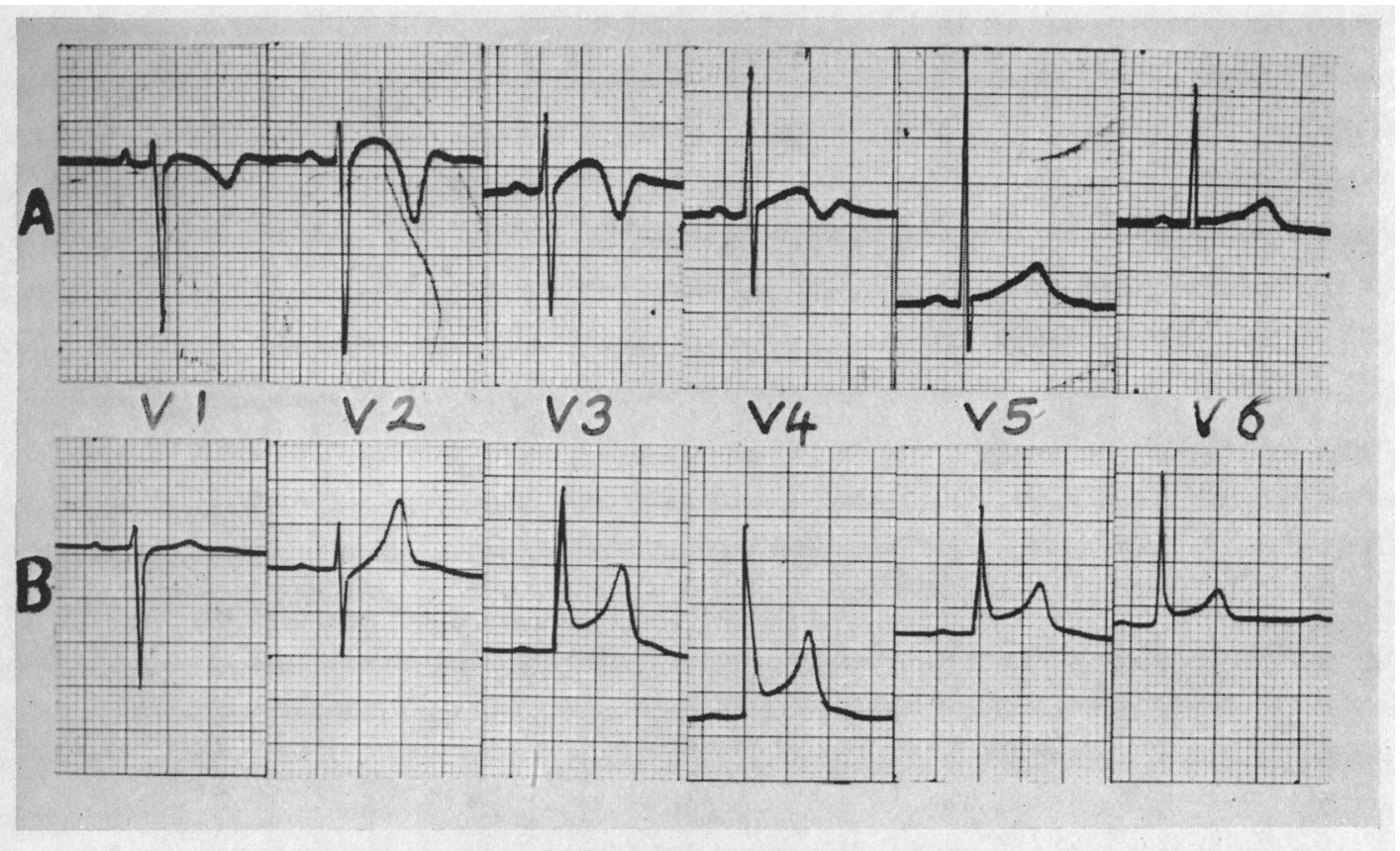

FIG. 1.-(A) African man, aged 30, with amœbic dysentery. Typical electrocardiographic Pattern 1 over right ventricular surface leads. (B) Healthy African man, aged 28. Typical electrocardiographic Pattern 2 over left ventricular surface leads.

Of the 63 patients in Group 2 with normal patterns on admission, 58 remained normal, 4 developed Pattern 1, and 1 developed Pattern 2 after being in hospital. Of the 23 with Pattern 1 on admission, 10 continued to show this pattern, 10 became normal, 2 developed Pattern 2, and 1 developed Pattern 1 and 2. Of the 10 with Pattern 2 on admission, 8 continued to show this pattern and 2 became normal. Of the 4 with Pattern 1 and 2 on admission, 1 continued to show this pattern, 1 became normal, and 2 developed Pattern 2.

The finding that Pattern 1 occurs predominantly over the right ventricular surface leads, and Pattern 2 over the left ventricular surface leads is similar to that of Grusin (1954). Table III indicates that these changes are not limited to the younger age groups.

Effect of Exercise and Respiration. When the T waves were deeply inverted, exertion tended to reduce the amount of inversion, and when it was initially shallow, exercise frequently caused it to become upright. In subjects with Pattern 2 changes, exercise invariably reduced the S-T segment

TABLE I

Comparative Incidence of Abnormal Patterns in Three Groups of Africans and in Grusin's Subjects

\begin{tabular}{|c|c|c|c|c|c|}
\hline & \multirow{2}{*}{ No. of cases } & \multicolumn{4}{|c|}{ Percentage } \\
\hline & & Abnormal & Pattern 1 & Pattern 2 & Pattern 1 and 2 \\
\hline 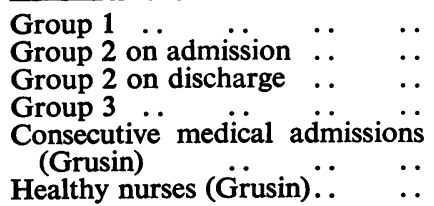 & $\begin{array}{r}100 \\
100 \\
100 \\
50 \\
159 \\
50\end{array}$ & $\begin{array}{l}39 \\
37 \\
29 \\
22\end{array}$ & $\begin{array}{r}32 \\
23 \\
14 \\
2\end{array}$ & $\begin{array}{r}5 \\
10 \\
13 \\
20\end{array}$ & $\begin{array}{r}2 \\
4 \\
2 \\
-\end{array}$ \\
\hline
\end{tabular}




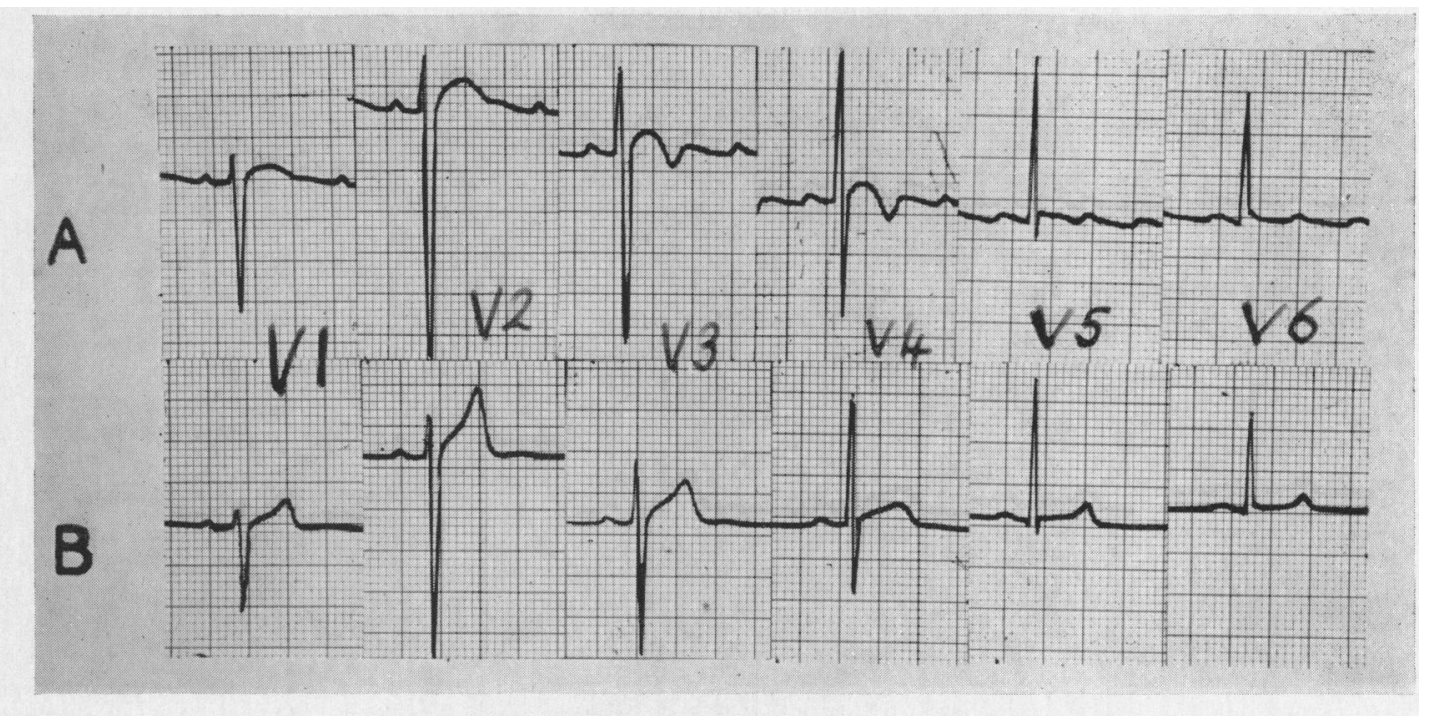

Fig. 2.-African man, aged 36, with amœbic dysentery. (A) Electrocardiographic Pattern 1 on admission. (B) Normal electrocardiogram on discharge 18 days later.

TABLE II

Distribution of Abnormal Patterns over the Ventricular Leads

\begin{tabular}{|c|c|c|c|c|c|c|c|c|c|}
\hline & \multicolumn{3}{|c|}{ Over right ventricle } & \multicolumn{3}{|c|}{ Over left ventricle } & \multicolumn{3}{|c|}{ Over both ventricles } \\
\hline & Group 1 & Group 2 & Group 3 & Group 1 & Group 2 & Group 3 & Group 1 & Group 2 & Group 3 \\
\hline $\begin{array}{ll}\text { Pattern } 1 & \ldots \\
\text { Pattern } 2 & \ldots \\
\text { Pattern } 1 \text { and } 2 & . .\end{array}$ & $\underline{19}$ & $\begin{array}{ll}15 & (8)^{*} \\
- & -\end{array}$ & $\frac{1}{-}$ & $\begin{array}{l}6 \\
5 \\
-\end{array}$ & $\begin{array}{rr}4 & (5)^{*} \\
10 & (13) \\
2 & (2)\end{array}$ & $\overline{10}$ & $\frac{7}{2}$ & $\frac{4}{2} \stackrel{(1)^{*}}{-}$ & 三 \\
\hline
\end{tabular}

* The figures in brackets give the number on discharge, the first figures being the number on admission.

elevation to accepted normal levels. Deep inspiration had a similar, but somewhat smaller, effect than exercise. These effects are identical with those observed by Grusin (1954).

Other Data. No correlation could be found between the electrocardiographic patterns and the serum electrolytes, hæmatology, liver function tests, and liver biopsy. In all instances radiographs and screening of the heart were normal.

\section{Discussion}

This work is largely a repetition of Grusin's (1954), and the results are in accord with his observations that these electrocardiographic changes usually fall into one of two patterns. There is a similar incidence of Pattern 1 in the consecutive medical admissions, but in my series the proportion with Pattern 2 is much smaller, and conversely in the African male nursing staff, although there is a similar percentage of abnormal patterns, they are nearly all Pattern 2 in my subjects. In a study of apparently healthy Africans, Brink (1956) found Pattern 1 in only a small proportion while Pattern 2 was common. Despite the S-T segment elevation, he emphasized that the shape of the segment is always normal. It seems clear that in the cases of amœbic dysentry (Group 2) there is a greater tendency for Pattern 1 to become normal after treatment in hospital than there is for Pattern 2. In no instance did a subject with Pattern 2 subsequently develop Pattern 1. It is possible that these 


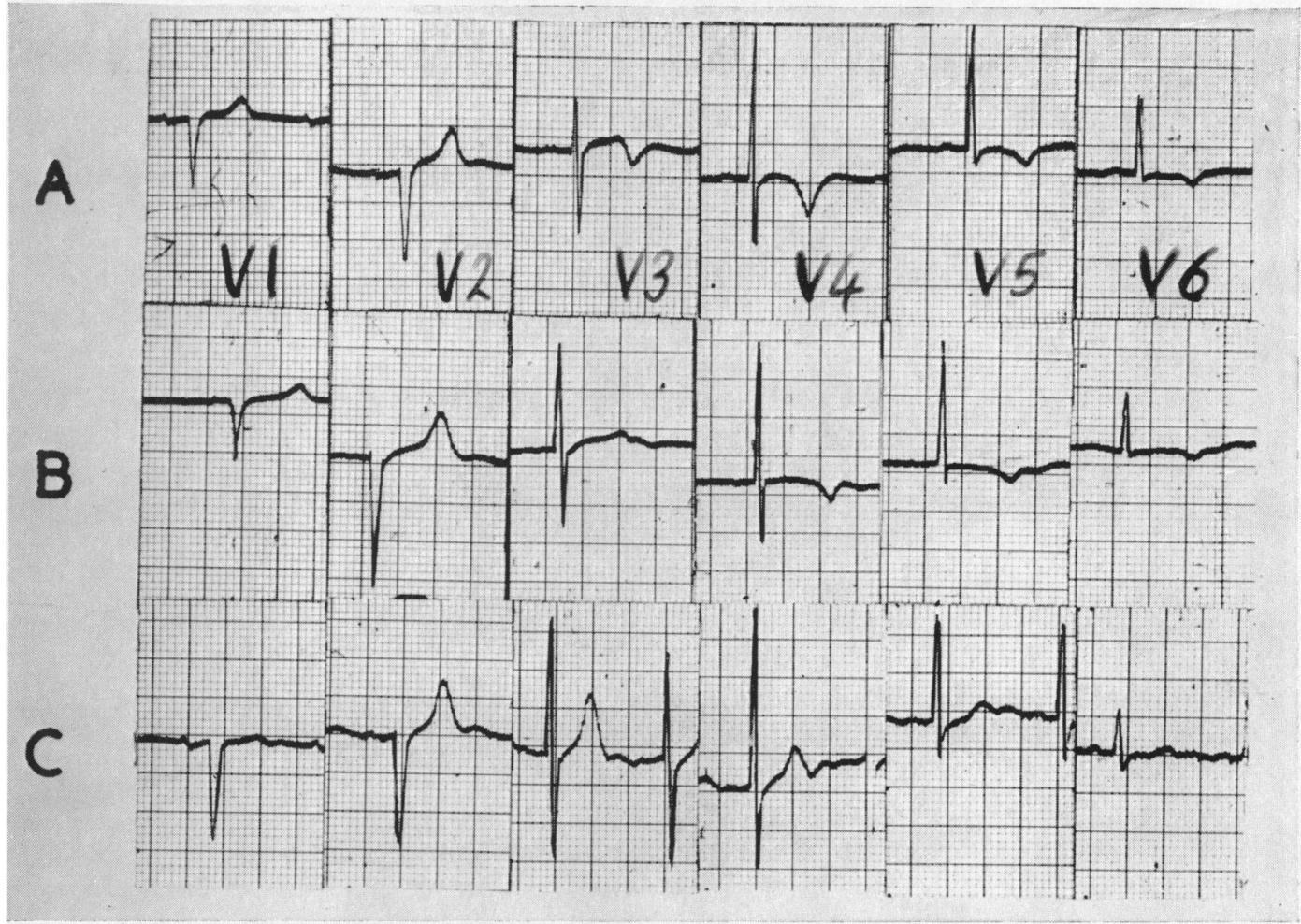

Fig. 3.-African man, aged 75, no heart disease. (A) Electrocardiographic Pattern 1 on admission. (B) Pattern less marked 9 days later. (C) Electrocardiogram taken immediately after exercise, when the $T$ waves have now become upright.

patterns are due to unrelated causes, and it may be that Pattern 2 is a normal variant, particularly as it is more common in our healthy, well-nourished Africans.

These S-T segment and $\mathrm{T}$ wave changes simulate those found in organic heart disease, but neither Grusin (1954) nor myself have found any abnormalities at autopsy. Clinical and pathological evidence of heart disease due to coronary ischæmia is rare in the African, particularly in the age

TABLE III

Age Distribution and Cardiographic Findings in Africans

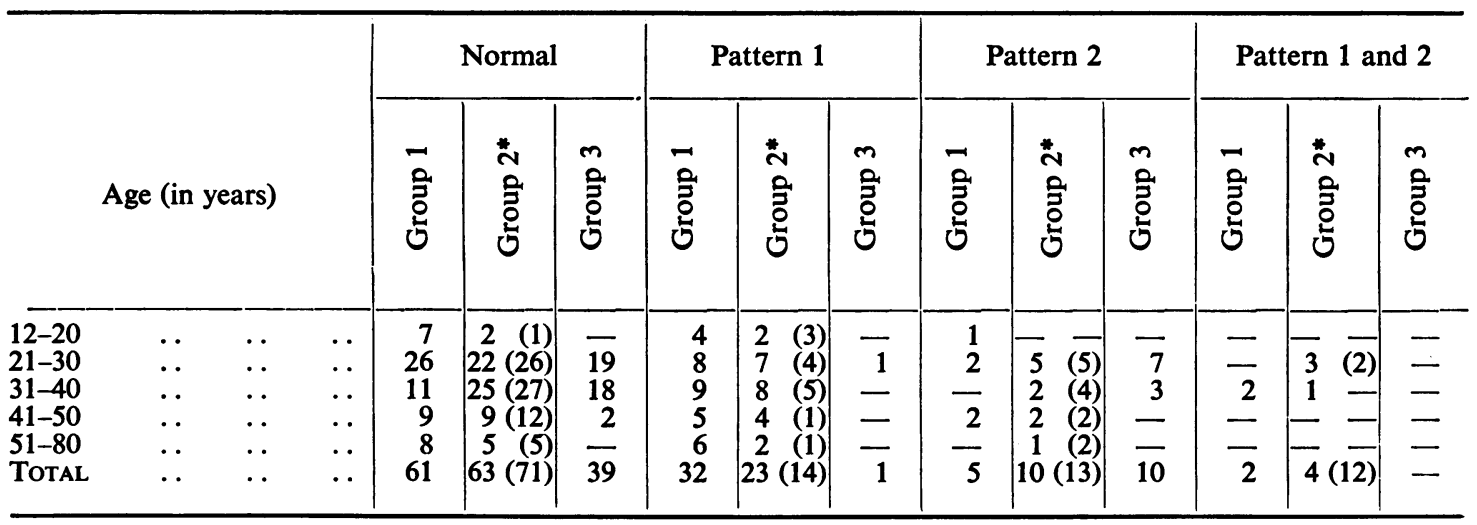

* The figures in brackets give the number on discharge, the first figures being the number on admission. 
groups in which these cardiographic changes are most commonly seen (Becker, 1946; Higginson et al., 1952; and Wainwright, 1958).

In view of the frequency of cardiomyopathies of obscure ætiology and widespread malnutrition in the African, it is tempting to ascribe these changes to similar factors, but we have few grounds for such an assumption. Gillanders (1951) describing 20 African patients with cardiomyopathies noted that the commonest electrocardiographic abnormality was a curve of subepicardial injury, which became normal in usually not less than ten weeks. Becker et al. (1953) also found depressed S-T segments and flat or inverted $\mathrm{T}$ waves to be common in their cases of cardiomyopathy. These changes are similar to our Pattern 1, and it is therefore possible that their occurrence in cardiomyopathy is coincidental. Ball et al. (1954) do not report this pattern in their cases of cardiomyopathy occurring in Uganda. It is true that subendocardial fibrosis and myocardial fibrosis of unknown ætiology is found in a small proportion of Africans who come to autopsy without clinical heart disease, but the incidence is far too slight to account for these common and widespread electrocardiographic patterns (Wainwright, 1958).

In view of the frequency of siderosis and cirrhosis of the liver in the South African Bantu it has been suggested that siderosis of the myocardium might be responsible for these changes and also for the development of myocardiopathies. Wainwright (1958) therefore investigated the incidence of siderosis of the liver and myocardium in 50 consecutive African necropsies over the age of 25 years and found that, whereas 34 cases showed siderosis of the liver, only 3 had diffuse siderosis of the myocardium, while 4 others had occasional siderotic myocardial fibres. The three cases with diffuse siderosis of the myocardium all had severe siderosis and cirrhosis of the liver. Necropsies were also performed on 30 Africans who died in congestive cardiac failure, the group comprising 10 cases each of hypertension, rheumatic valvular disease, and myocardiopathy of unknown ætiology. Seven of the cases with hypertensive heart disease, 5 with rheumatic valvular disease, and 2 with myocardiopathy of unknown ætiology showed siderosis of the liver, but in no case was diffuse siderosis of the myocardium found. Higginson et al. (1952) have also noted the absence of siderosis of the myocardium in their cases of myocardiopathy. It would therefore appear that siderosis of the myocardium cannot be a factor in producing these electrocardiographic changes.

The striking feature in both Grusin's (1954) and this series is the day to day variation in these patterns and the effect of exercise and deep respiration on them. This lability renders an organic change most unlikely and points to a functional cause. Pattern 1 is similar to the so-called Juvenile Pattern. The extent of these changes, its presence in all age groups of Africans, and the fact that it tends to disappear after being in hospital makes Littman's (1946) hypothesis, that in the American Negro Pattern 1 is due to an infantile bodily habitus, unlikely. Goldberger (1953) favours a relative potassium deficiency to account for this pattern. Although I have been unable to correlate the serum electrolytes with these changes in my cases, this by no means rules out changes in the myocardial electrolyte concentration as a factor. Drummond (1957), reviewing the genesis of the S-T segment and $\mathrm{T}$ wave, has emphasized that their form depends on a primarily biochemical return to normal in the myocardial cell. Grusin (1954) suggested that liver disease may in some way be responsible for a metabolic factor producing these cardiographic changes. However, if this were so there ought to be a higher incidence of such changes in patients with clinical liver disease, and one would expect the changes to become more pronounced in the older age groups. I have been unable to correlate clinical, biochemical, or liver biopsy evidence of liver disease with these patterns. In the absence of positive evidence the most reasonable explanation of the $\mathrm{S}-\mathrm{T}$ segment and $\mathrm{T}$ wave changes in the African is a biochemical change in the myocardial cell due to unknown factors.

\section{SUMMARY}

Electrocardiograms with bizarre $\mathrm{S}-\mathrm{T}$ segment and $\mathrm{T}$ wave changes, which could be classified according to Grusin's criteria, were found in 39 per cent of 100 medical non-cardiac African patients, in 22 per cent of African male nursing staff, and in 37 per cent of 100 African male cases of amœbic 
dysentry. Following treatment 29 per cent of the cases with amœbic dysentery still showed these changes.

It is suggested that the two main patterns are due to unrelated causes. The ætiology of these changes is discussed.

I wish to thank Dr. J. Wainwright, Senior Lecturer, Dept. of Pathology, University of Natal for access to pathological records; Dr. A. O. Lurie for assistance with the electrocardiograms; and Dr. S. Disler, Medical Superintendent, King Edward VIII Hospital for facilities.

\section{REFERENCES}

Ball, J. D., Williams, A. W., and Davies, J. N. P. (1954). Lancet, 2, 1049.

Becker, B. J. P. (1946). S. Afr. J. med. Sci., $11,97$.

Chatgidakis, C. B., and van Lingen, B. (1953). Circulation, 7, 345.

Brink, A. J. (1951). S. Afr. J. Clin. Sci., 2, 288.

(1956). S. Afr. J. Lab. Clin. Med., $2,97$.

Drummond, J. K. (1957). S. Afr. med. J., 31, 1245.

Gillanders A. D. (1951). Brit. Heart J., 13, 177.

Goldberger, E. (1953). Unipolar Lead Electrocardiography. 3rd ed., London.

Goldman, M. J. (1953). Amer. Heart J., 46, 817.

Grusin, H. (1954). Circulation, 9, 860.

Higginson, J., Gillanders, A. D., and Murray, A. F. (1952). Brit. Heart J., 14, 213.

Littmann, D. (1946). Amer. Heart J., 32, 370.

Wainwright, J. (1958). Personal Communication. 